\title{
Snoring and Mortality in Patients with Heart Failure and Dialysis
}

\author{
Tomoyuki Kawada \\ Department of Hygiene and Public Health, Nippon Medical School, Bunkyo-Ku, Tokyo, Japan
}

I read with interest the paper 'Snoring amplifies the risk of heart failure (HF) and mortality in dialysis patients' by Torino et al. [1]. The paper is a cohort study with a median follow-up period of 2.3 years, and the authors concluded that snoring was a strong and independent effect modifier on the relationship between chronic heart failure and mortality in dialysis patients. I have some concerns on their study outcome.

First, insomnia is prevalent in patients with end-stage renal disease undergoing dialysis [2], and the rate of prevalence of obstructive sleep apnea syndrome (OSAS) in patients with hemodialysis (HD), continuous ambulatory peritoneal dialysis (CAPD) and automated peritoneal dialysis (APD) were 36,65 and $60 \%$, respectively. Torino et al. analyzed data from 827 patients; this group consisted of $773 \mathrm{HD}$ patients and 54 PD patients. Snoring is an important indicator of sleep-disordered breathing (SDB), and I suppose that the type of dialysis should be considered for their further analysis, because PD is suspected to be strongly associated with snoring.

Second, the percentage of patients without a snoring habit was $39.3 \%$, and HF patients with snoring showed a significant risk of all-case and cardio-vascular mortalities. When the level of snoring became severe, the hazard ratios increased. In such a situation, treatment for snoring or SDB is needed to improve prognosis of the patients with HF. I agree with the authors' conclusion and randomized controlled study would accelerate their recommendation.

Third, beta-blocker therapy is associated with a lower risk of death or heart failure hospitalization among patients with chronic kidney disease and heart failure [3]. I suppose that the content of medication should be specified for their statistical analysis.

Finally, Cengić et al. reported that the prevalence of snoring, daytime napping and breathing problems in 200 patients with $\mathrm{HD}$ were 47,34 and $30 \%$, respectively [4]. As the sensitivity of snoring for SDB by sleep polysomnography was $39 \%$, the two-step screening method for selecting patients with SDB is needed from the past study and data from the present study.

Torino et al. understand their study limitations and therefore, further study is required to confirm their study outcome.

\section{Disclosure Statement}

No potential conflicts of interest were disclosed.

\section{Conflicts of Interest}

I have no conflicts of interest in this study.

\section{References}

$\rightarrow$ Torino C, Mattace-Raso F, van Saase JL, D'Arrigo G, Tripepi R, Tripepi GL, Postorino M, Mallamaci F, Zoccali C; PROGREDIRE Working Group: Snoring amplifies the risk of heart failure and mortality in dialysis patients. Am J Nephrol 2014;39:536-542.
Losso RL, Minhoto GR, Riella MC: Sleep disorders in patients with end-stage renal disease undergoing dialysis: comparison between hemodialysis, continuous ambulatory peritoneal dialysis and automated peritoneal dialysis. Int Urol Nephrol 2014, Epub ahead of print.

-3 Chang TI, Yang J, Freeman JV, Hlatky MA, Go AS: Effectiveness of $\beta$-blockers in heart failure with left ventricular systolic dysfunction and chronic kidney disease. J Card Fail 2013;19:176-182.
Cengić B, Resić H, Spasovski G, Avdić E, Alajbegović A: Quality of sleep in patients undergoing hemodialysis. Int Urol Nephrol 2012;44:557-567.

\section{KARGER}

E-Mail karger@karger.com

www.karger.com/ajn
( 2015 S. Karger AG, Base

0250-8095/15/0406-0571\$39.50/0
Tomoyuki Kawada, MD

Department of Hygiene and Public Health Nippon Medical School

1-1-5 Sendagi, Bunkyo-Ku, Tokyo 113-8602 (Japan)

E-Mail kawada@nms.ac.jp 